\title{
Studies on the Protein Defect in Tangier Disease
}

\author{
ISOLATION AND CHARACTERIZATION OF AN ABNORMAL \\ HIGH DENSITY LIPOPROTEIN
}

\author{
Samuel E. Lux, Robert I. Levy, Antonio M. Gotto, and \\ Donald S. Fredrickson \\ From the Molecular Disease Branch, National Heart and Lung Institute, \\ Bethesda, Maryland 20014
}

A в S T R A C T High density lipoproteins (d 1.063-1.210 $\mathrm{g} / \mathrm{ml}$ ) were isolated from the plasma of normal individuals (HDL) and seven homozygous patients with Tangier disease (HDLr). In Tangier patients, the concentration of protein in the high density region (HDL $)$ was only $0.5-4.5 \%$ of normal. Immunochemical studies, including mixing experiments conducted in vivo and in vitro, indicated that $\mathrm{HDL}_{\mathrm{T}}$ was different from HDL. HDL ${ }_{\mathrm{T}}$ was the only high density lipoprotein detectable in the plasma of Tangier homozygotes. In heterozygotes both HDL and HDL were present. HDL was not detected in the plasma of over 300 normal persons and 10 patients with secondary high density lipoprotein deficiency and appeared to be a unique marker for Tangier disease.

ApoHDL contained two major apoproteins designated apoLp-Gln-I and apoLp-Gln-II; together they comprised $85-90 \%$ of the total protein content. Both of the major HDL apoproteins were present in apoHDLr; but apoLp-Gln-I was disproportionately decreased with respect to apoLp-Gln-II, the ratio of their concentrations being $1: 12$ in apoHDL as compared with $3: 1$ in apoHDL. Several minor apoprotein components which together comprise $5-15 \%$ of apoHDL were present in approximately normal proportions in apoHDLr. In the HDL of Tangier patients it was estimated that, compared with normal individuals, the concentration of apoLp-Gln-I was decreased about 600 -fold and the con-

This work was presented in part at the Meeting of the Society for Pediatric Research, Atlantic City, N. J., 2 May 1970 (Pediat. Res. 4 : 439).

Dr. Gotto's present address is Department of Medicine, Baylor University College of Medicine, Houston, Tex.

Received for publication 21 December 1971 and in revised form 27 April 1972. centration of apoLp-Gln-II about 17 -fold. The decrease in these apoproteins was not due to preferential segregation with the lipoprotein fractions of $\mathrm{d}<1.063 \mathrm{~g} / \mathrm{ml}$ or with the plasma proteins of $\mathrm{d}>1.21 \mathrm{~g} / \mathrm{ml}$. Tangier apoLp-Gln-I and apoLp-Gln-II appeared to be immunochemically identical with their normal counterparts, and no differences between the two sets of apoproteins were detected on polyacrylamide gel electrophoresis at $\mathrm{pH}$ 9.4 or 2.9. These results are most compatible with the hypothesis that the hereditary defect in Tangier disease is a mutation in an allele-regulating synthesis of apoLp-Gln-I.

\section{INTRODUCTION}

Tangier disease is a rare autosomal recessive disorder characterized by the near absence of plasma high density lipoprotein and the storage of cholesteryl esters in foam cells in many tissues (1). Prominent clinical features include splenomegaly, enlarged, orange-colored tonsils, and a relapsing sensory-motor neuropathy which may be quite disabling $(1,2)$.

Recent observations (3-6) indicate that $\mathrm{HDL}^{1}$ contains two major apoproteins (apoLp-Gin-I and apoLp-

\footnotetext{
${ }^{1}$ Abbreviations used in this paper: HDL, high density lipoproteins, isolated from normal plasma between d 1.063-1.210 $\mathrm{g} / \mathrm{ml} ; \mathrm{HDL}_{\mathrm{T}}$, high density lipoproteins, isolated from plasma of patients with Tangier disease between $d 1.063-1.210 \mathrm{~g} / \mathrm{ml}$; LDL, low density lipoproteins, isolated from normal plasma between d $1.019-1.063 \mathrm{~g} / \mathrm{ml}\left(\mathrm{S}_{\mathrm{f}} 0-12\right)$; VLDL, very low density lipoproteins, isolated from fasting normal plasma at $\mathrm{d}<1.006 \mathrm{~g} / \mathrm{ml}\left(\mathrm{S}_{\mathrm{f}}>20\right)$; apoHDL, protein moiety of HDL; apoHDL , protein moiety of HDL ; HSA, human serum albumin. The apoprotein components of HDL are designated by the term "apoLp-" followed by the carboxylterminal amino acid. (continued on page 2506)
} 
Gln-II) and a group of minor apoproteins, including three which are also important apoprotein constituents of very low density lipoproteins (apoLp-Ser, apoLp-Glu, and apoLp-Ala) (7-9). These apoproteins can be purified by chromatography in dissociating agents such as urea $(3,4)$ or acetic acid $(5)$ and have been characterized in several laboratories (3-19 and footnote 2). Complete amino acid sequences of apoLp-Ala (12) and apoLp-Gln-II (13) are known as well as a portion of the sequence of apoLp-Gln-I (19). These apoproteins are now believed to have a variety of functions in lipid metabolism in addition to their ability to solubilize and transport lipids. ApoLp-Glu has been shown to stimulate lipoprotein triglyceride lipase activity (20-22). ApoLp-Gin-I and apoLp-Gin-II stimulate and inhibit, respectively, lecithin-cholesterol acyltransferase, the plasma enzyme which synthesizes cholesterol esters by the transfer of a fatty acid from lecithin to unesterified cholesterol (23). ApoLp-Gln-II can also substitute for liver squalene-sterol carrier protein in facilitation of cholesterol biosynthesis (24). Finally, apoLp-Ser, apoLp-Glu, and apoLp-Ala are known to cycle between very low density lipoprotein (VLDL) and HDL in the course of metabolism of VLDL (25). Tangier disease provides a unique opportunity to investigate the consequences of the near absence of some of these apoproteins and alteration in the distribution of others on lipid metabolism.

Preliminary experiments disclosed the presence of traces of a HDL (d 1.063-1.21), designated HDL Tangier plasma and suggested that HDL $\mathrm{T}$ was immunochemically distinguishable from normal HDL (26). In the present study, the immunochemical properties of the Tangier high density lipoprotein were further examined, and techniques for HDL protein fractionation

Designation in Other Systems of Nomenclature

\begin{tabular}{|c|c|c|c|c|c|c|}
\hline Apoprotein & $\begin{array}{l}\text { Carboxyl- } \\
\text { terminal } \\
\text { amino acid }\end{array}$ & $\begin{array}{l}\text { Kostner } \\
\text { and } \\
\text { Alaupovic } \\
(6,7)\end{array}$ & $\begin{array}{c}\text { Shore } \\
\text { and } \\
\text { Shore } \\
(3)\end{array}$ & $\begin{array}{c}\text { Brown } \\
\text { et al. } \\
(8,9)\end{array}$ & $\begin{array}{l}\text { Scanu } \\
\text { et al. } \\
\text { (4) }\end{array}$ & $\begin{array}{c}\text { Rudman } \\
\text { et al. } \\
\text { (5) }\end{array}$ \\
\hline apoLp-Gln-I & $\begin{array}{l}\text { Threonine (3) } \\
\text { Glutamine (6) }\end{array}$ & $A-I$ & R-Thr & - & III & II, C \\
\hline apoLp-Gln-II & Glutamine $(3,6)$ & A-II & R-Gln & 一 & IV & III, D \\
\hline apoLp-Ser & Serine $(10,11)$ & C-I & - & D1 & & \\
\hline apoLp-Glu & $\begin{array}{l}\text { Glutamic Acid } \\
\quad(9-11)\end{array}$ & C-II & - & D2 & $\mathrm{V}$ & - \\
\hline apoLp-Ala & Alanine $(8,11)$ & C-III & R-Ala & D3, D4 & & 一 \\
\hline
\end{tabular}

Although previously considered to be threonine, the carboxylterminal residue of apoLp-Gin-I has recently been shown to be glutamine (6), a finding that we have confirmed. ${ }^{2}$ ApoLpSer $(10)$ is identical to the previously misnamed apoLp-Val (8). In several instances where microheterogeneity of a particular apoprotein exists the different forms of the protein are designated by a subscript. Thus, apoLp-Ala contains a mixture of apoLp-Ala ${ }_{1}$ and apoLp-Ala 2 .

${ }^{2}$ Lux, S. E., and K. M. John. 1972. Further characterization of the polymorphic forms of a human high density apolipoprotein, apo-GIn-I (apoA-I). Submitted for publication. were employed to investigate the composition of HDLт. In particular, we were interested in the relative amounts of apoLp-Gln-I and apoLp-Gln-II in the Tangier HDL and in comparison of the isolated Tangier apoproteins with their normal counterparts.

\section{METHODS}

Patients. Seven patients homozygous for Tangier disease (Pe. Lo., Pa. Lo., T. La., E. La., J. Mi., C. Mi., and C. No.) who came from four unrelated kindreds and two sets of heterozygous parents (E. Lo., M. Lo., G. La., and P. La.) were donors of the Tangier plasma used in this report. All of these patients have been described in detail in previous reports from this laboratory $(1,27-30)$. Also sampled were 10 patients with secondary deficiency of HDL due to severe liver disease $(31,32)$, a number of patients with various types of hyperlipoproteinemia, and over 300 normal individuals with normal lipoprotein levels and electrophoretic patterns.

Dictary studies. The details of the dietary protocol for "carbohydrate induction" and its effects on the plasma lipids and lipoprotein fractions in four of the Tangier homozygotes, two sets of parents and normal subjects have been previously described (32). In all of these subjects, the intake of an isocaloric diet containing greater than $7 \mathrm{~g}$ carbohydrate $/ \mathrm{kg}$ body weight caused the concentration of plasma triglycerides to rise and the concentration of HDL to fall. These effects were apparent within 2 days and appeared to be maximal at about 7 days (32).

Transfusion. One patient homozygous for Tangier disease, Pe. Lo., underwent open heart surgery for correction of pulmonic stenosis. Samples of her blood were obtained before the operation, and a large volume (2 liters) was removed as the patient was about to go on cardiopulmonary bypass. During and immediately after surgery, the patient received $10 \mathrm{U}$ of normal whole blood in addition to that used to prime and maintain the blood level in the oxygenator. Blood samples were obtained at the conclusion of surgery, every $4 \mathrm{hr}$ during the 1st postoperative day, twice daily for 3 more days, and then daily for 10 days. During the first 4 days after the operation, the patient was febrile and received most nourishment intravenously. She lost some fluid by drainage from her thoracotomy wound, but no additional blood or plasma was administered in the postoperative period.

Isolation of lipoprotcins. Plasma, obtained by venopuncture or plasmapheresis of patients or normal subjects who had fasted overnight, was collected in $0.01 \%$ EDTA and stored at $4^{\circ} \mathrm{C}$. Fractionations were begun within $48 \mathrm{hr}$ of collection. Tangier and normal plasmas were carried through all of the subsequent physical and chemical separations in parallel.

Initially, HDL was separated by the method of Havel, Eder, and Bragdon (33). Subsequently, a modification of this procedure was used. In the modified procedure, the plasma was raised to a density of 1.063 by the addition of solid $\mathrm{KBr}$. The plasma was then centrifuged at $15^{\circ} \mathrm{C}$ in a Spinco model L2 preparative ultracentrifuge (Beckman Instruments, Inc., Spinco Div., Palo Alto, Calif.) at 60,000 $\mathrm{rpm}$, using a $60 \mathrm{Ti}$ rotor, for $16 \mathrm{hr}\left(2.44 \times 10^{8} \mathrm{~g}-\mathrm{min}\right)$. The tubes were sliced $25 \mathrm{~mm}$ below the tops, the infranatant fraction adjusted to d 1.210 with additional $\mathrm{KBr}$, and recentrifuged at $60,000 \mathrm{rpm}$ in the $60 \mathrm{Ti}$ rotor for $24 \mathrm{hr}$ $\left(3.66 \times 10^{8} \mathrm{~g}\right.$-min $)$. The d 1.120 supernatant fraction, obtained by slicing the tubes $19 \mathrm{~mm}$ below the tops, was raised to $\mathrm{d} 1.215$ and washed twice by layering under a d 1.210 
$\mathrm{KBr}$ solution and centrifuging at $40,000 \mathrm{rpm}$ in a 40 rotor for $48 \mathrm{hr}\left(3.04 \times 10^{8} \mathrm{~g}\right.$-min $)$. Appropriate blanks of identical salt composition and density were included in each rotor and used to determine the salt density of the supernatant and infranatant fractions after each centrifugation. The yield of unwashed HDL agreed with the yield predicted from determination of $\mathrm{HDL}$ cholesterol in the starting plasma (34), and published values for the per cent cholesterol in HDL (35).

For quantitation of plasma $\mathrm{HDL}$ in small samples of plasma, the plasma density was raised to 1.063 by the addition of $\mathrm{NaCl}$ and $\mathrm{KBr}$ (33) and the plasma centrifuged in a 40.3 rotor for $16 \mathrm{hr}$. The top and bottom fractions were obtained by tube slicing and brought to the concentration of the starting plasma by addition of $0.9 \% \mathrm{NaCl}$ solution. HDL concentration was defined in terms of the cholesterol in the bottom fraction.

Measurement of HDL by precipitation of $L D L$ and VLDL. $0.15 \mathrm{ml}$ of $0.1 \mathrm{M}$ manganese chloride and $6 \mathrm{mg}$ of sodium heparin were added to $3-\mathrm{ml}$ portions of plasma (36). A precipitate was allowed to form for $15 \mathrm{~min}$ at $4^{\circ} \mathrm{C}$, and then the plasma was centrifuged for $15 \mathrm{~min}$ at $4^{\circ} \mathrm{C}$. HDL is not precipitated by this procedure. The heparin-manganese supernates were always checked for contamination with VLDL and LDL by use of immunoelectrophoresis with antisera to LDL; none was found.

Delipidation and solubilization. Lipoproteins were delipidated with ethanol-diethyl ether $(1: 3 \mathrm{v} / \mathrm{v})$ at $4^{\circ} \mathrm{C}$ as previously described (38). They contained less than $0.4 \%$ phospholipid by weight (16). The apoproteins were completely soluble in aqueous buffers above $\mathrm{pH}$ 7.0.

Fractionation of $H D L$ apoproteins. $\mathrm{HDL}$ apoproteins for use as purified standards were isolated by a combination of the published techniques of gel filtration and ion-exchange chromatography $(3,4)$. Delipidated apoproteins were completely dissolved at a concentration of $8-12 \mathrm{mg} / \mathrm{ml}$ in $0.2 \mathrm{M}$ Tris- $\mathrm{HCl}$ buffer containing $0.01 \%$ EDTA and $6 \mathrm{M}$ urea at $\mathrm{pH}$ 8.2. $10-50 \mathrm{mg}$ were fractionated by Sephadex G-200 chromatography in a manner similar to that described by Scanu, Toth, Edelstein, Koga, and Stiller (4), with the minor modification that the column was equilibrated and eluted with $0.2 \mathrm{M}$ Tris- $\mathrm{HCl}$ containing $0.01 \%$ EDTA and $6 \mathrm{M}$ urea at $\mathrm{pH}$ 8.2. However, because it was difficult to obtain apoLP-GIn-II completely free of apoLP-Gin-I by this method and because the apoLP-Gln-I and "minor protein" (fraction V of Scanu et al. [(4)] peaks could be fractionated further by ion-exchange chromatography, the Sephadex fractions were often further purified by chromatography on diethylaminoethyl (DEAE)-cellulose in $6 \mathrm{~m}$ urea, using a modification ${ }^{3}$ of the procedure described by Shore and Shore (3). With this procedure, apoLp-Gln-II eluted earlier than apoLp-Gln-I and was judged to be pure by polyacrylamide gel electrophoresis and its unique amino acid composition (i.e., absence of histidine, arginine, and tryptophan). ${ }^{3}$ The "minor-protein" fraction was resolved into four principal components by DEAE-cellulose chromatography. These corresponded to the four proteins (apoLp-Ser, apoLp-Glu, apoLp-Ala 1 , and apoLp-Ala $\mathrm{a}_{2}$ ) that are also major components of VLDL (8-10). Several additional minor components representing $<1 \%$ of the total HDL protein remained and were not identified.

${ }^{3}$ Lux, S. E., K. M. John, and H. B. Brewer, Jr. 1972. The amino acid sequence of apoLp-Gln-II, a human plasma high density apolipoprotein. I. Isolation and characterization of apoLp-Gln-II (apoA-II). Submitted for publication.
To retard carbamylation of proteins (39), urea solutions were passed over a mixed bed ion-exchange resin (Rexyn I-300, Fisher Scientific Co., Pittsburgh, Pa.) ; and buffers made with this de-ionized urea were stored at $4^{\circ} \mathrm{C}$ and replenished every $24-48 \mathrm{hr}$ during experiments conducted at room temperature. With Sephadex G-200 chromatography, elution volumes were determined by weighing tared tubes and correcting the difference in weight for density of the buffer. The volumes were expressed as $\mathrm{K}_{\mathrm{av}}=\left(\mathrm{V}_{0}-\mathrm{V}_{\mathrm{o}}\right)$ / $\left(V_{t}-V_{o}\right)$ where $V_{e}$ represents the elution volume of the substance, $V_{o}$, the void volume, and $V_{t}$, the total bed volume of the column (40). Void volumes were determined using blue dextran (Pharmacia Fine Chemicals Inc., Piscataway, N. J.). Column fractions were monitored for protein by their absorbance at 280 or $230 \mathrm{~nm}$ and dialyzed against $0.01 \%$ EDTA, $\mathrm{pH} 8.2$, using No. 18 cellulose casing (Union Carbide Corp., New York).

Storage of apoprotcins. Apoprotein solutions were stored up to 30 days at $4^{\circ} \mathrm{C}$ and for longer periods at $-20^{\circ} \mathrm{C}$. It was found that apoproteins stored in solution at $4^{\circ} \mathrm{C}$, particularly in the presence of urea, showed a gradual change in polyacrylamide gel electrophoresis patterns over 1-6 months (and occasionally as early as $2 \mathrm{wk}$ ). The earliest observed change was usually a separation of the apoLpGln-II into two bands; later the single, broad apo-Lp-Gln-I band split into multiple ones. These changes were considered to be artifactual since they were usually not present in freshly prepared samples of apoLp-Gln-I or apoLp-Gln-II. They were not accompanied by detectable alterations in immunochemical properties. Apoproteins stored frozen in solution at $-20^{\circ} \mathrm{C}$ in the absence of urea or lyophilized and stored at 4 or $-20^{\circ} \mathrm{C}$ showed none of these changes for periods up to 6 months.

Immunochemistry. Antisera prepared as described previously (37) were characterized as shown in Table I and stored frozen in small lots. Equivalence points were determined semiquantitatively using the device described by Piazzi (41). Parallel rows of five wells were created in an immunodiffusion plate, the wells in one row decreasing, those in the adjacent row increasing in size. The wells in the two rows were so arranged that each well in one row was equidistant from two wells in the opposite row. The volume of the wells were $50,20,10,5$, and $2.5 \mu 1$. By placing antigen in one row and antibody in the other, nine reactions were observed with antigen: antibody ratios (micrograms antigen: microliters antibody) of $2.5 x: 50,2.5 x: 20,5 x: 20$, $5 x: 10,10 x: 10,10 x: 5,20 x: 5,20 x: 2.5$, and $50 x: 2.5$ (where $x=$ antigen concentration). For purposes of comparison, the ratios were normalized to $1 \mu \mathrm{g}$ of antigen, giving antigen: antibody ratios from $(1: 20)(x)$ to $1: 0.05(x)$. The antigen:antibody ratios were exactly reproducible if run on the same day but varied with time due to alterations in antibody titers on prolonged storage at $4^{\circ} \mathrm{C}$. Equivalence points and titers were checked at the time each batch of antibody was thawed and every $4 \mathrm{wk}$ thereafter.

Absorption of antibodies was carried out with sufficient antigen to produce an antigen: antibody ratio fivefold greater than the antigen: antibody ratio at equivalence. The precipitates were allowed to stand $48-72 \mathrm{hr}$ at $4^{\circ} \mathrm{C}$ before the absorbed sera were harvested (42).

Toward the end of the study, monospecific antisera were isolated by coupling $10 \mathrm{mg}$ of highly purified apoLp-Gln-I or apoLp-Gln-II to $10 \mathrm{ml}$ of packed Sepharose 4B (Pharmacia Fine Chemicals, Inc.) using procedures described by Cuatrecasas (43). The Sepharose apoLp-Gin-I and Sepharose apoL $L_{\mathrm{p}} \mathrm{Gln}-\mathrm{II}$ were washed free of unbound protein 
TABLE I

Characterization of Antisera

\begin{tabular}{|c|c|c|c|c|c|c|c|c|c|c|}
\hline \multirow[b]{2}{*}{ Antibod $y^{*}$} & \multirow{2}{*}{$\begin{array}{l}\text { Previous } \\
\text { designation } \\
\text { (37) }\end{array}$} & \multirow[b]{2}{*}{$\begin{array}{l}\text { Immunizing } \\
\text { antigen }\end{array}$} & \multirow[b]{2}{*}{$\begin{array}{l}\text { Prepared } \\
\text { in }\end{array}$} & \multicolumn{7}{|c|}{ Reactivity* } \\
\hline & & & & $\begin{array}{c}\text { ApoLp- } \\
\text { Gln-I }\end{array}$ & $\begin{array}{l}\text { ApoLp- } \\
\text { Gln-II }\end{array}$ & $\begin{array}{l}\text { ApoLp- } \\
\text { Ser }\end{array}$ & $\begin{array}{l}\text { ApoLp- } \\
\text { Glu }\end{array}$ & $\begin{array}{c}\text { ApoLpl- } \\
\text { Ala }\end{array}$ & LDL $\ddagger$ & HSA $\ddagger$ \\
\hline Anti-HDL-1 & $S_{1}$ & $\mathrm{HDL}$ & Sheep & + & + & \pm & 0 & 0 & + & + \\
\hline Anti-HDL-2 & $\mathrm{S}_{2}$ & HDL & Sheep & + & + & 0 & 0 & 0 & + & + \\
\hline Anti-HDL-3 & - & HDL $\$$ & Sheep & + & + & 0 & 0 & 0 & 0 & + \\
\hline Anti-HDL-4 & $\mathrm{R}_{2}$ & $\mathrm{HDL}$ & Rabbit & + & + & 0 & 0 & 0 & + & 0 \\
\hline Anti-HDL-5 & $\mathrm{R}_{4}$ & HDI. & Rabbit & 0 & + & $\mathrm{NT} \|$ & $\mathrm{NT}$ & $\mathrm{NT}$ & + & + \\
\hline Anti-HDL-6 & - & $\mathrm{HDL}$ & Rabbit & + & 0 & NT & $\mathrm{NT}$ & $\mathrm{NT}$ & $\mathrm{NT}$ & $\mathrm{NT}$ \\
\hline Anti-HDL-7 & $\mathrm{R}_{i}$ & $\mathrm{HDL}$ & Rabbit & \pm & 0 & NT & $\mathrm{NT}$ & NT & + & 0 \\
\hline Anti-HDL-8 & $\mathrm{R}_{3}$ & $\mathrm{HDI}$ & Rabbit & + & + & $\mathrm{NT}$ & NT & NT & + & + \\
\hline Anti-HDL-9 & $\mathrm{R}_{j}$ & $\mathrm{HDL}$ & Rabbit & + & + & $\mathrm{NT}$ & $\mathrm{NT}$ & $\mathrm{NT}$ & + & + \\
\hline Anti-HDL-10 & $\mathrm{R}_{6}$ & HDL & Rabbit & + & 0 & NT & $\mathrm{NT}$ & $\mathrm{NT}$ & + & + \\
\hline Anti-HDL ${ }_{T}$ & - & $\mathrm{HDL}_{\mathrm{T}} \boldsymbol{\top}$ & Rabbit & \pm & + & 0 & 0 & 0 & + & + \\
\hline Anti-apoLp-Gln-I** & - & - & - & + & 0 & \pm & 0 & 0 & + & + \\
\hline Anti-apoLp-Gln-II** & - & - & - & 0 & + & \pm & 0 & 0 & + & + \\
\hline Anti-HSAft & - & HSA & Rabbit & 0 & 0 & 0 & 0 & 0 & 0 & + \\
\hline Anti-LDL & - & LDI & Sheep & 0 & 0 & 0 & 0 & 0 & + & 0 \\
\hline
\end{tabular}

* Antibody reactivities were determined semiquantitatively against purified antigens as described in Methods. Reactivities are expressed at + (good reactivity; maximum antigen:antibody ratio $<1: 20$, \pm (weak reactivity, maximum antigen:antibody ratio $>1: 20$ ), 0 (no reaction seen).

$\$$ The difficulty in preparing HDL antisera free of reactivity to LDL and HSA has been noted previously (37).

$\S \mathrm{HDL}$ isolated from a patient with abetalipoproteinemia.

\| NT, not tested.

T Tangier HDL isolated from pooled plasma of Pe. Lo. and Pa. Lo.

** Anti-apoLp-Gln-I and anti-apoLp-GIn-II were prepared by absorption of anti-HDL-1 with a fivefold excess of chromatographically purified apoLp-Gln-II (anti-apoLp-Gln-I) or apoLp-Gln-I (anti-apoLp-Gln-II).

$\ddagger \ddagger$ Purchased from Hyland Laboratories, Los Angeles, Calif.

and packed into columns. Anti-HDL-1 (15 ml) was passed over each column and the bound antibody eluted with 0.1 II acetic acid adjusted to $\mathrm{pH} 3$ with $\mathrm{NaOH}$. The eluate was tested by immunoelectrophoresis against antisheep whole serum and was found to contain only $\gamma$-globulin which reacted specifically with the antigen bound to the Sepharose. Antibodies were concentrated by ultrafiltration and a portion of each was again bound to Sepharose 4B (50 mg antibody $/ \mathrm{ml}$ packed Sepharose) to produce columns of Sepharose anti-apoLp-Gln-I and Sepharose anti-apoLp-Gln-II.

Immunodiffusion was performed on $3 \frac{1}{2} \times 4$-inch glass slides coated with $10 \mathrm{ml}$ of $1 \%$ agarose (Seakem, Bausch \& Lomb, Inc., Rochester, N. Y.) in saline. The experiments were designed to produce reactions at or near equivalence. The plates were developed at $4{ }^{\circ} \mathrm{C}$ and were observed for at least 7 days. Immunoelectrophoresis in agar or agarose was carried out in veronal buffer at $\mathrm{pH} 8.2$ as previously described (37).

Polyacrylamide gel clectrophoresis. Polyacrylamide gel electrophoresis was performed in $0.6 \times 8.0-\mathrm{cm}$ tubes. Gels containing $10 \%$ acrylamide were run in $8 \mathrm{M}$ urea at $\mathrm{pH} 9.4$ (44) and $\mathrm{pH} 2.9^{4}$ and stained with $0.05 \%$ coomassie blue (Colab Laboratories, Inc., Glenwood, Ill.) as described by Chrambach, Reisfeld, Wyckoff, and Zaccari (45). Less than $0.5 \mu \mathrm{g}$ of apoLp-Gln-I or apoLp-Gln-II would be detected

4 The $\mathrm{pH} 2.9$ system was developed and kindly supplied by Dr. Ralph Reisfeld, Scripps Clinic Research Foundation, La Jolla, Calif. in the $\mathrm{pH} 9.4$ system. The sensitivity of the $\mathrm{pH} 2.9$ system was not determined.

Amino acid analysis. Amino acid analyses were performed with a Beckman-Spinco automatic amino acid analyzer (model 120B, Beckman Instruments, Inc., Spinco Div., Palo Alto, Calif.), adapted for high sensitivity (46) and a rapid elution schedule (47). The samples were hydrolyzed in $6 \mathrm{~N} \mathrm{HCl}$ for $22 \mathrm{hr}$ at $110^{\circ} \mathrm{C}$ in open tubes contained within a clamped, sealed desiccator. The desiccator was repeatedly evacuated and flushed with oxygen-free nitrogen before hydrolysis. By this technique both the Tangier and control samples were exposed to identical hydrolysis conditions. Cystine and tryptophan were destroyed completely by this procedure and were not determined separately. No corrections were made for possible degradation or incomplete hydrolysis of amino acid residues.

Other techniques. Protein (48), cholesterol (49), phospholipid (50), and triglyceride (51) concentrations were determined as previously described. Lipoprotein paper electrophoresis was performed in barbital buffer containing albumin (52). The strips were died at $100^{\circ} \mathrm{C}$ for $10 \mathrm{~min}$ and stained for protein with bromphenol blue or for lipid with Oil Red-O (32).

\section{RESULTS}

Isolation of $H D L_{r}$. No $\alpha$-lipoprotein band was obtained after paper electrophoresis of plasma from the seven patients homozygous for Tangier disease. Less 
than $4 \mathrm{mg} / 100 \mathrm{ml}$ of cholesterol were recovered in either the density 1.063-1.210 ultracentrifugal fraction or in the supernatant fraction after VLDL and LDL were precipitated from these plasmas with heparin and manganese. In normal subjects, ultracentrifugation or precipitation yields $35-70 \mathrm{mg} \mathrm{HDL}$ cholesterol $/ 100 \mathrm{ml}$ of plasma (34).

In every patient, however, a faint precipitin line having $\alpha$ mobility was obtained by reacting whole plasma with antisera made to HDL (Fig. 1B). The small amount of lipoprotein isolated from each of the Tangier patients after ultracentrifugation between 1.063 and 1.210 contained this reactivity (Fig. 1D). It was also present in the supernatant layer obtained by precipitation of the plasma fraction of $<1.210$ with heparin and manganese. No precipitin line with $\alpha$ mobility was obtained when the plasma fractions of $>1.210$ or of $<1.063$ were reacted with any of the 10 different HDL antisera.

Characterization of $H D L_{r}$. The average lipid contents of HDLт, as measured in three separate samples, were: triglycerides $(13.3 \%)$, free cholesterol $(9.2 \%)$, cholesteryl esters $(26.1 \%)$, and phospholipids (51.2\%). HDL $L_{x}$ had $\alpha_{1}$ electrophoretic mobility on agar or agarose gel (Fig. 1D), or on paper. The mobility of HDL was slightly slower than that of HDL when they were coelectrophoresed on agar or agarose (Fig. 1E).

Preparations of HDLr isolated from each of the homozygotes reacted with each of the 10 anti-HDL sera and appeared to be immunochemically identical with each other. All of the antisera to HDL except antiHDL-5 revealed apparent antigenic differences between HDL ${ }_{\mathrm{T}}$ and its normal counterpart in the form of one or more spur lines at the junction of the precipitin lines formed by HDL and HDL

The antiserum made to $\mathrm{HDL}_{\mathrm{T}}$ reacted with $\mathrm{HDL}$ from normal subjects and patients with Tangier disease (Fig. 1C, 1D). Absorption of the anti-HDLt serum with either HDLт or HDL removed all reactivity to either form of HDL. This is in contrast to the results obtained when the antisera made to HDL were absorbed with HDLr. All, except anti-HDL-5, reacted with normal HDL after all reactivity with $\mathrm{HDL}_{\mathbf{T}}$ was removed. These initial immunochemical experiments indicated that HDL and HDL were immunochemically similar but not identical. Since anti-HDL-5 was the only HDL antiserum lacking reactivity to apoLp-Gln-I, (Table I), they suggested that apoLp-Gln-I was missing from HDL $\mathrm{H}_{\mathrm{T}}$ or was present in an immunochemically altered form.

In vivo studies of $H D L_{r}$. The partial exchange transfusion occurring in patient $\mathrm{Pe}$. Lo. provided an unusual opportunity to document the apparent immunochemical uniqueness of HDL through an in vivo

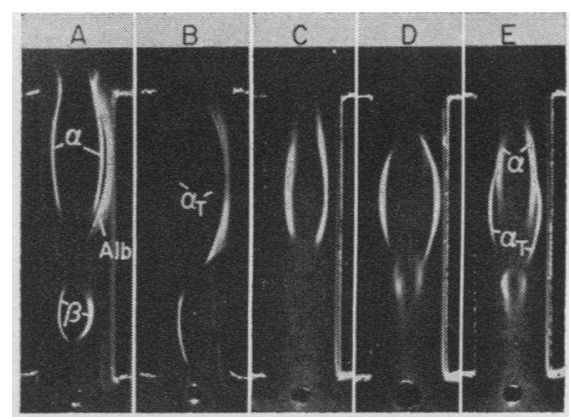

Figure 1 Comparisons of normal and Tangier plasma and $\mathrm{HDL}$ by immunoelectrophoresis in agarose. Antigens are: A, normal plasma; B, Tangier plasma; C, $1.063-1.210 \mathrm{~g} / \mathrm{ml}$ fraction of normal plasma (HDL); D, 1.063-1.210 g/ml fraction of Tangier plasma $\left(\mathrm{HDL}_{\mathrm{T}}\right) ; \mathrm{E}$, mixture of equal amounts of $\mathrm{HDL}$ and $\mathrm{HDL}_{\mathrm{T}}$. Antibodies were: $\mathrm{A}$ and $\mathrm{B}$ anti-HDL-8 (left) and anti-HDL-5 (right). C, D, and E anti-HDL-1 (left) and anti-HDL (right). Precipitin lines corresponding to $\mathrm{HDL}(\alpha), \operatorname{LDL}(\beta), \mathrm{HDL}_{\mathrm{T}}\left(\alpha_{\mathrm{T}}\right)$, and human albumin (Alb) are designated in the figure.

mixing experiment (Fig. 2). The patient had normal concentrations of HDL $(36 \mathrm{mg} / 100 \mathrm{ml})$ immediately after cardiopulmonary bypass. The concentration fell to $29 \mathrm{mg} / 100 \mathrm{ml} 8 \mathrm{hr}$ later, and to $10 \mathrm{mg} / 100 \mathrm{ml} 48 \mathrm{hr}$ after surgery. These changes were accompanied by a marked fall in the titer of immunoreactive HDL. Between the 2nd and 4th postoperative days, a second $\alpha$-lipoprotein precipitin line of slightly slower mobility appeared on immunoelectrophoresis (Fig. 2). The normal HDL precipitin line had almost disappeared by the 6th day.

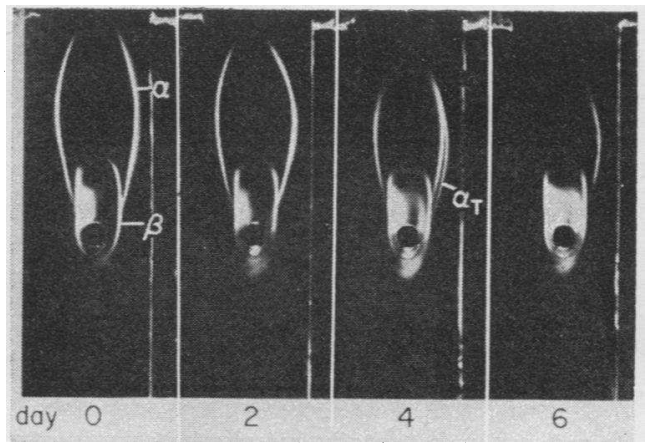

FIGURE 2 Immunoelectrophoresis in agar of serial samples of plasma from Tangier patient Pe. Lo. after a massive transfusion with normal plasma. The details of this study are presented in Methods. The antisera employed were antiHDL-1 (right trough) and anti-HDL-2 (left trough). Both antisera were absorbed to remove anti-albumin reactivity. Immunoprecipitin lines corresponding to HDL $(\alpha)$ and LDL $(\beta)$ are designated in the pattern produced on day 0 . On day 4 a second $\alpha$-migrating immunoprecipitin reaction corresponding to $\mathrm{HDL}_{T}\left(\alpha_{T}\right)$ is seen. By day 6 only the $\alpha_{T}$ reaction remains. The reaction of $\mathrm{HDL}_{\mathbf{T}}$ with antiHDL-2 is present but is much fainter than the reaction with anti-HDL-1. 


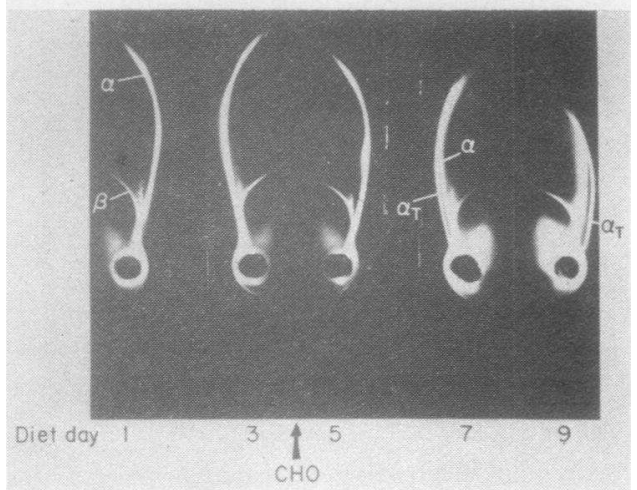

FIGURE 3 Immunoelectrophoresis in agar of serial plasma samples from G. La., a Tangier heterozygote, before and after lowering of HDL levels by a diet high in carbohydrate $(\mathrm{CHO})$. The details of this study are presented in Methods. The anti-serum employed was anti-HDL-1 which had been absorbed to remove anti-albumin reactivity. Immunoprecipitin lines corresponding to HDL $(\alpha)$ and LDL $(\beta)$ are designated in the pattern produced on day 1 . On day 7 , a second $\alpha$-migrating immunoprecipitin reaction corresponding to $\mathrm{HDL}_{\mathrm{T}}\left(\alpha_{\mathrm{T}}\right)$ is seen. This latter reaction is dominant in the sample procured on day 9.

HDL $L_{\text {in }}$ Tangier heterozygotes. On a standard American diet, the Tangier heterozygotes had HDL cholesterol concentrations between 22 and $30 \mathrm{mg} / 100 \mathrm{ml}$. Only one precipitin band was obtained by immunoelectrophoresis when their plasmas were reacted with the anti-HDL sera. Two HDL lines were obtained when the plasmas were diluted twofold; similar dilution of normal plasma produced only one line. The HDL con-

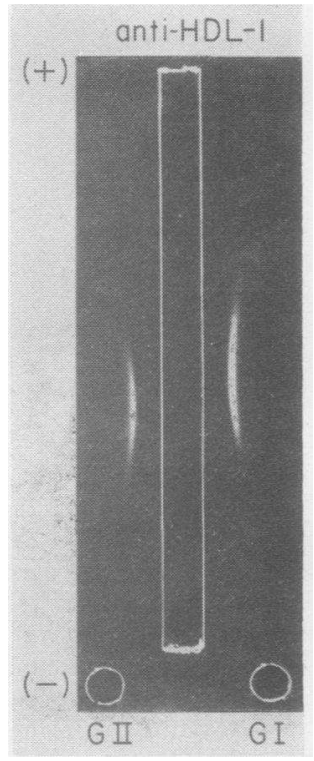

FIGURE 4 Immunoelectrophoresis in agarose of apoLp-Gin-I (GI) and apoLp-Gln-II (GII) against anti-HDL-1. Antigen concentrations were $0.1 \mathrm{mg} / \mathrm{ml}$. Photograph at $24 \mathrm{hr}$.

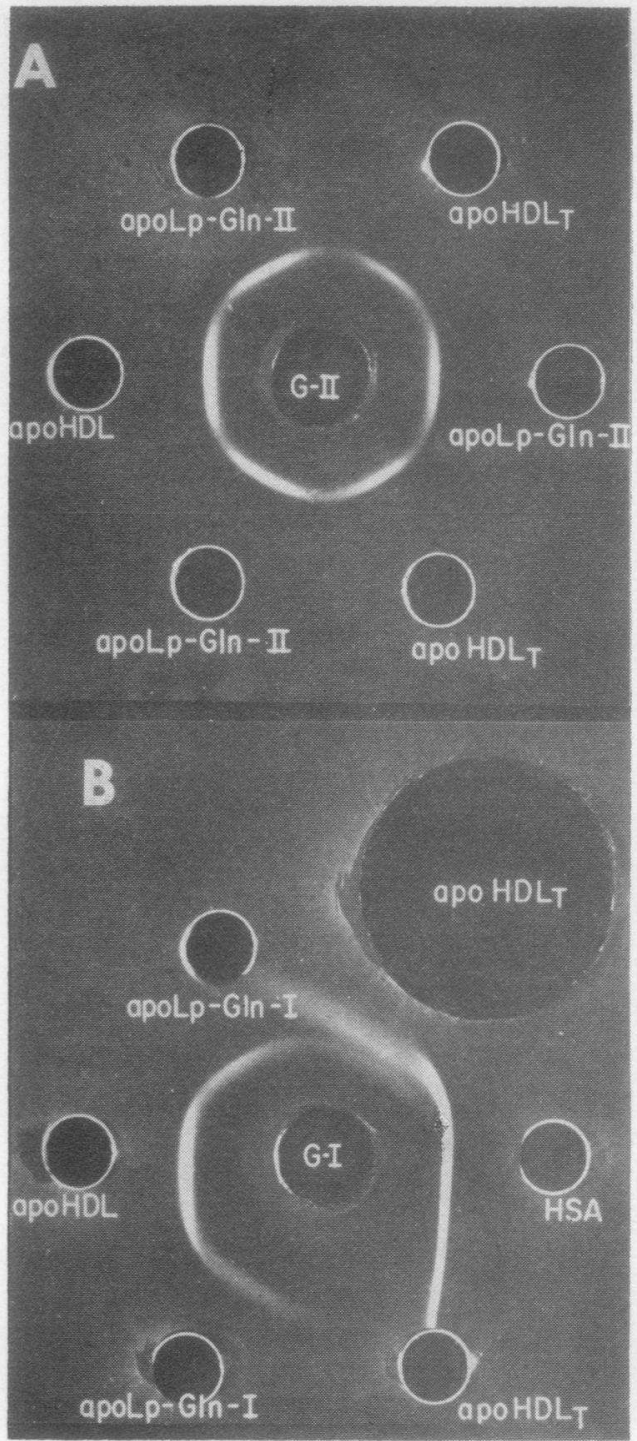

Figure 5 Comparison of Tangier (apoHDL ${ }_{\mathrm{T}}$ ) and normal (apoHDL) high density apoproteins by double diffusion in agarose against anti-apoLp-Gln-II (GII) in $A$ and antiapoLp-Gln-I (GI) in B. These antisera were made by absorption of anti-HDL-1 with either apoLp-Gln-I or apoLpGin-II. They also reacted with albumin (Table I). The apoHDL $_{\mathrm{T}}$ was from $\mathrm{Pe}$. Lo. Protein concentrations were identical in both experiments: HDL $(0.4 \mathrm{mg} / \mathrm{ml})$, apoLp)Gln-II $(0.1 \mathrm{mg} / \mathrm{ml})$, apoLp-Gln-I $(0.1 \mathrm{mg} / \mathrm{ml})$, and human serum albumin (HSA) $(0.5 \mathrm{mg} / \mathrm{ml})$. The large well in the experiment in B contained 24 times the volume of the smaller wells. Photograph at $36 \mathrm{hr}$.

centrations of each of four heterozygotes were considerably reduced by feeding a high carbohydrate diet, and a second and more slowly migrating precipitation line then became apparent (Fig. 3). When 15 normal subjects and more than 20 patients with primary hyperlipoproteinemia were similarly fed the high carbohy- 
drate diet, their plasma HDL cholesterol concentrations were also reduced; in 7 of these individuals, the concentration of HDL cholesterol fell below $15 \mathrm{mg} / 100 \mathrm{ml}$. Nevertheless only one HDL precipitin line was ever observed at the nadir of the HDL concentration. Immunoelectrophoresis of whole plasma from 10 patients with hepatocellular disease (HDL cholesterol concentrations of $6-10 \mathrm{mg} / 100 \mathrm{ml}$ ) likewise revealed only a single HDL precipitation line. The HDL from these 10 patients was isolated by ultracentrifugation and was immunochemically identical with normal HDL and not identical with HDLr.

Immunochemical studies of apoHDLr. In preliminary experiments, apoLp-Gin-I and apoLp-Gln-II were shown to be immunochemically nonidentical in their reactions with the anti-HDL sera $1-4$ (Table I) and with anti-HDLr. ApoLpGin-I had a slightly faster electrophoretic mobility than apoLp-Gln-II (Fig. 4).

The earlier suggestion that apoLp-Gin-I might be missing or immunochemically abnormal in HDLr was tested more definitively in the experiment shown in Fig. 5. Anti-HDL-1 was made specific for either apoLp-Gln-I or apoLp-Gln-II by absorption with the alternate antigen. This antiserum also reacted with albumin. As shown in Fig. 5A, both apoHDL and apoHDL contained an

TABLE II

Anti-apoLp-Gln-I and anti-apoLp-Gln-II Reactivity of an Antiserum to Normal High Density Lipoprotein after Absorption with Normal or Tangier High Density A poproteins

\begin{tabular}{|c|c|c|}
\hline Antibody* & Antigen & $\begin{array}{c}\text { Maximum } \\
\text { antigen: } \\
\text { antibody } \\
\text { ratioł }\end{array}$ \\
\hline Anti-HDL-1 + saline & $\begin{array}{l}\text { apoLp-GIn-I } \\
\text { apoLp-GIn-II }\end{array}$ & $\begin{array}{c}\mu g: \mu l \\
>1: 0.5 \\
>1: 0.5\end{array}$ \\
\hline Anti-HDL-1 + apoHDL $\$$ & $\begin{array}{l}\text { apoLp-Gin-I } \\
\text { apoLp-Gln-II }\end{array}$ & $\begin{array}{c}1: 10 \\
<1: 200\end{array}$ \\
\hline Anti-HDL-1 + apoHDL & $\begin{array}{l}\text { apoLp-GIn-I } \\
\text { apoL,p-Gln-II }\end{array}$ & $\begin{array}{l}<1: 200 \\
<1: 200\end{array}$ \\
\hline
\end{tabular}

* Equal volumes of an antiserum to normal human high density lipoprotein (anti-HDL-1) were absorbed with equal amounts of either normal (anti-HDL-1 + apoHDL) or Tangier (anti-HDL-1 + apoHDL ) high density apoprotein. An equal volume of saline was added to a third volume of antiserum (anti-HDL-1 + saline) as a dilutional control.

‡ Semiquantitative titers were obtained as described in Methods. The higher antigen to antibody ratio of $1: 0.5$ represents a greater titer than $1: 10 ;<1: 200$ indicates no reaction was seen. Antigen concentrations were $0.1 \mathrm{mg} / \mathrm{ml}$. All reactions were run on the same day.

$\S$ The apoHDL $\mathrm{T}$ was isolated from Pe. Lo. plasma.

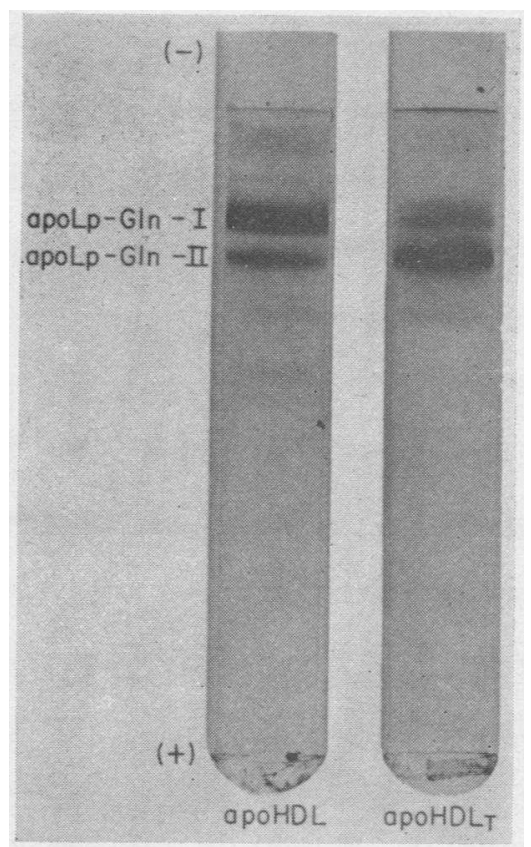

FIGURE 6 Polyacrylamide gel electrophoresis of equal amounts of normal (apoHDL) and Tangier (apoHDL T $_{\text {) high }}$ density apoproteins. The apoHDL $\mathbf{T}$ was obtained from $\mathrm{Pa}$. Lo. Gels containing $20 \mu \mathrm{g}$ of protein were run at $\mathrm{pH} 9.4$ in $8 \mathrm{M}$ urea and stained with coomassie blue. The acrylamide concentration was $10 \%$. The labeled bands correspond to apoLp-Gln-I and apoLp-Gln-II, the major proteins of HDL.

antigen which was immunochemically identical with normal apoLp-Gin-II. In contrast (Fig. 5B), antiapoLp-Gln-I demonstrated immunochemically normal apoLp-Gin-I in apoHDL but did not react with the same amount of apoHDLr. However, if the amount of apoHDL ${ }_{\mathrm{T}}$ was increased 12-fold (not shown) or 24-fold (large well in Fig. 5B), two immunoprecipitin lines appeared; one immunochemically identical with normal apoLp-Gln-I and the other identical with human serum albumin, a trace reactant in this preparation. Two additional observations confirmed the presence of small amounts of apoLp-Gln-I in apoHDL. Firstly, an antiserum to HDL $_{\mathrm{T}}\left(\operatorname{anti-HDL_{T})}\right.$ reacted weakly with chromatographically purified apoLp-Gin-I (Table I, Fig. 10C). This reactivity was removed by absorption with apoLp-Gln-I but not with apoLp-Gln-II. Secondly, absorption of an antiserum to normal HDL with apo-

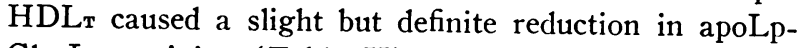
Gin-I reactivity (Table II). In the latter experiment, equal volumes of anti-HDL-1 were absorbed with equal amounts of either apoHDL or apoHDL absorbed all detectable reactivity with either apoLp-Gin-I or apoLp-Gln-II (maximum antigen: antibody ratio $<1: 200)$. ApoHDL ${ }_{\mathrm{T}}$, on the other hand, absorbed all reactivity with apoLp-Gin-II but only decreased the titer of anti-apoLp-Gln-I reactivity from $1: 0.5$ to $1: 10$. 


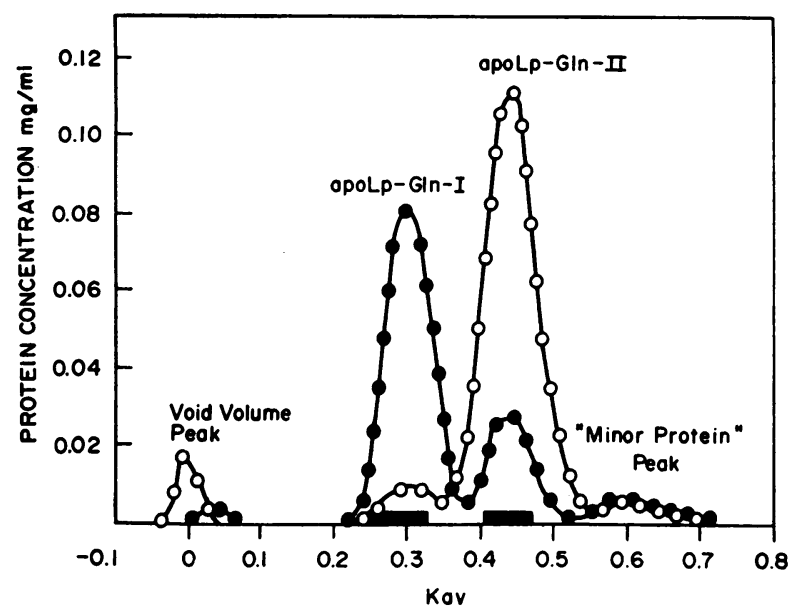

FIgURE 7 Sephadex G-200 chromatography of equal amounts of apoHDL (-—) and apoHDL $\left(\mathrm{O}_{\mathrm{T}} \longrightarrow \mathrm{O}\right)$. $10 \mathrm{ml}$ of each apoprotein were dissolved in $0.2 \mathrm{M}$ Tris- $\mathrm{HCl}$ $6 \mathrm{~m}$ urea, $0.01 \%$ EDTA, $\mathrm{pH} 8.2$, applied to a $2.5 \times 120 \mathrm{~cm}$ column of Sephadex G-200 and eluted with same buffer at a flow rate of $6 \mathrm{ml} / \mathrm{hr}$. The effluent volume is expressed as $\mathrm{K}_{\mathrm{av}}$ (see Methods). The apoHDL $\mathrm{T}_{\mathrm{T}}$ was obtained from $\mathrm{Pa}$. Lo. The portions of the apoLp-Gln-I and apoLp-Gln-II peaks marked by the bars were pooled and used for subsequent studies.

These immunochemical experiments indicated that both of the major HDL apoproteins were present in Tangier HDL but suggested a marked decrease in the ratio of apoLp-Gln-I to apoLp-Gln-II compared with that in normal HDL.

Polyacrylamide gel electrophoresis of apoHDLr. The results of the immunochemical experiments were confirmed qualitatively by polyacrylamide gel electrophoresis (Fig. 6). At $\mathrm{pH} 9.4$ apoLp-Gln-I and apoLp-Gin-II differed in their relative mobilities. In apoHDL, apoLpGln-I produced a broader and more intense band than apoLp-Gln-II, consistent with the approximate apoLpGln-I : apoLp-Gln-II ratio of $3: 1$ previously reported $(4,5,17)$. When the same quantity of apoHDL $\mathrm{L}_{\mathrm{T}}$ was examined under identical conditions, there was an intensely staining band with the mobility of apoLp-Gln-II and one or two very faint bands in the region of apoLpGln-I. Similar results were obtained with apoHDLt from four patients studied (Pe. Lo., Pa. Lo., T. La., and E. La.). Human serum albumin migrated in the same position as apoLp-Gln-I in the $\mathrm{pH} 9.4$ system, and the possibility that one or both of the faint "apoLp-Gln-I" bands were attributable to albumin was considered. However, when a very large load of apoHDL $(300 \mu \mathrm{g})$ was run at $\mathrm{pH} 9.4$ and slices of the unstained gel then tested by immunodiffusion, both apoLp-Gln-I and albumin were identified in the band corresponding in mobility to apoLp-Gln-I.

Gel filtration chromatography of apoHDLr. The protein components of Tangier HDL from one patient
(Pa. Lo.) were isolated and quantified by Sephadex G-200 chromatography in $6 \mathrm{~m}$ urea. The results are presented in Fig. 7. $10 \mathrm{mg}$ of apoHDL $\mathrm{T}_{\mathrm{T}}$ and apoHDL were chromatographed in succession on the same column. Recoveries were 96 and $92 \%$, respectively. The elution pattern of normal apoHDL showed the usual 3 to 1 predominance of apoLp-Gln-I (69\%) over apoLp-Gln-II $(23 \%)$. The Tangier apoprotein pattern was different, there being a 12 to 1 predominance of apoLp-Gln-II $(83 \%)$ over apoLp-Gln-I $(7 \%)$.

The percentage of the total protein eluted in the void volume was $1 \%$ for apoHDL and $5 \%$ for apoHDLr. Both of these values are within the usually observed range $(4,5)$. The content of the two void volume peaks differed however, as determined immunochemically. The apoHDL void volume peak contained primarily apoLpGln-I. with only a trace of apoLp-Gln-II, while the predominant component of the apoHDL ${ }_{\mathrm{r}}$ void volume peak was apoLp-Gln-II with traces of apoLp-Gln-I.

The proportion of the total protein appearing in the "minor protein" peaks was comparable for apoHDL $(7 \%)$ and apoHDL $(5 \%)$. A polyacrylamide gel electrophoretic comparison of the two "minor protein"

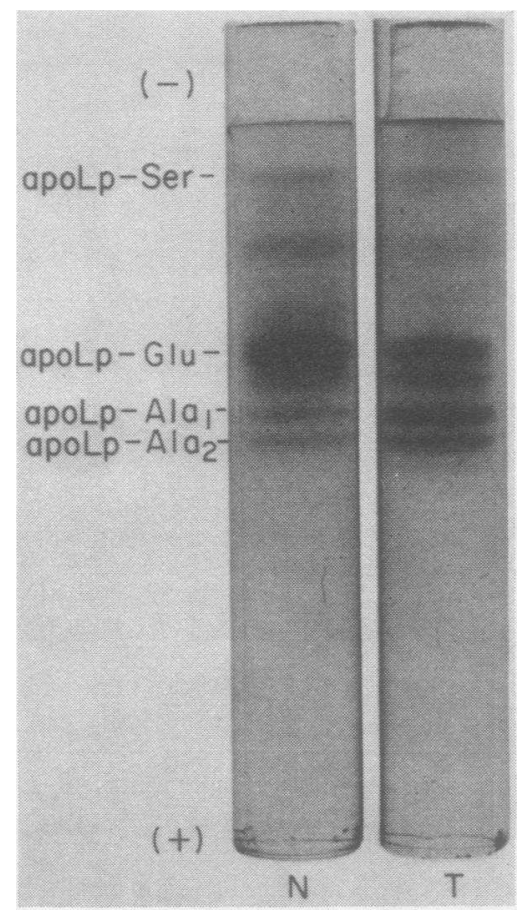

Figure 8 Polyacrylamide gel electrophoretic comparison of the minor protein fraction from Sephadex G-200 chromatography of normal $(\mathrm{N})$ and Tangier (T) HDL. $15 \mu$ of each fraction were applied to $10 \%$ gels, run at $\mathrm{pH} 9.4$ in $8 \mathrm{M}$ urea, and stained with coomassie blue. Bands corre-

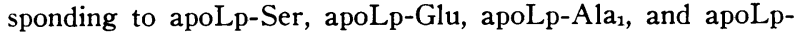
$\mathrm{Ala}_{2}$ (9) are labeled. The remaining bands represent unidentified proteins present in both apoHDL and apoHDL . $_{\text {. }}$ 


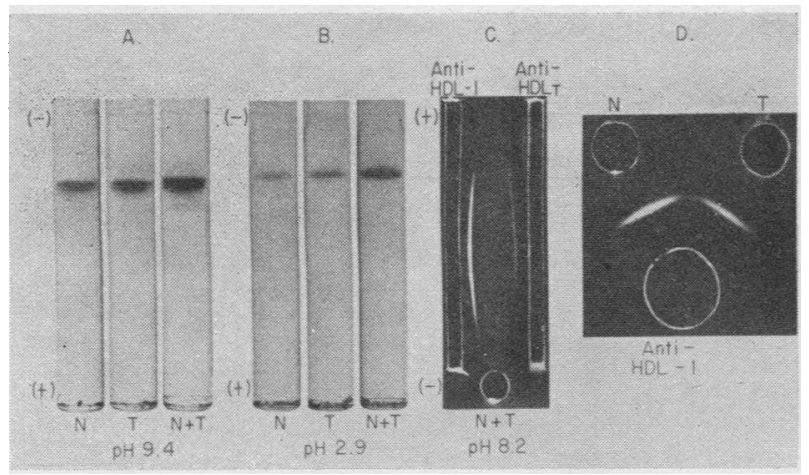

FIgURE 9 Comparison of Tangier and normal $a p o L p-G \ln -I I$. A, polyacrylamide gels contained $7.5 \mu \mathrm{g}$ of either Tangier (T) or normal (N) apoLp-Gln-II or $7.5 \mu \mathrm{g}$ of each $(\mathrm{N}+\mathrm{T})$, and were run as described in Fig. 6; $\mathrm{B}$, same samples run at $\mathrm{pH} 2.9 ; \mathrm{C}$, immunoelectrophoresis in agarose of a mixture of equal amounts of normal and Tangier apoLp-Gln-II $(\mathrm{N}+\mathrm{T})$ against anti-HDL-1 and anti-HDL $\mathrm{T}_{\mathrm{T}}$ (photograph at $24 \mathrm{hr}$ ); D, immunodiffusion in agarose of equal amounts of Tangier ( $T$ ) and normal (N) apoLpGln-II against anti-HDL-1. The antigen concentration was $0.1 \mathrm{mg} / \mathrm{ml}$. Photograph at $36 \mathrm{hr}$.

fractions is presented in Fig. 8. Bands corresponding in mobility to apoLp-Ser, apoLp-Glu, apoLp-Ala1, and apoLp-Alaz were observed in both preparations. Another obvious major band appeared between apoLp-Glu and apoLp-Ala. Its identity is currently under investigation in this laboratory. Several other minor bands remain to be identified. All visible bands were present in both apoHDL and apoHDLr, although, based on intensity of the stained bands, some variation in the relative proportions of the different components was apparent.

Comparison of the isolated Tangier and normal apoproteins. The apoproteins isolated from normal and Tangier HDL were further compared to see if any differences could be detected (Figs. 9 and 10). In order to avoid cross-contamination, only the fractions comprising the middle third of the apoLp-Gin-II peak and the first two-thirds of the apoLp-Gln-I peak were used. No difference in the electrophoretic mobility of Tangier and normal apoLp-Gln-II run separately or mixed was detected at either $\mathrm{pH} 9.4$ or $\mathrm{pH} 2.9$ (Figs. 9A and 9B). At $\mathrm{pH}$ 9.4, both apoLp-Gln-II bands appeared as a doublet. This was considered to be a storage artifact, as described in Methods, since only a single apoLp-Gln-II band was present when these same preparations were first examined following isolation (Fig. 6). Using immunoelectrophoresis and double immunodiffusion we could detect no difference between normal and Tangier apoLp-Gln-II with anti-HDL sera $1-4$ or anti-HDL. Representative reactions are shown in Figs. 9C and 9D. All of the protein in both apoLp-Gin-II preparations was removed by a single passage over a column of Sepharose anti-apoLp-Gln-II. The polyacrylamide gel patterns ( $\mathrm{pH}$ 2.9) were unchanged after passage over a column of Sepharose anti-apoLp-Gln-I.

Similarly, no difference was detected between Tangier and normal apoLp-Gin-I following polyacrylamide gel electrophoresis at either $\mathrm{pH} 9.4$ (Fig. 10A) or 2.9 (Fig. 10B). In the $\mathrm{pH} 2.9$ system, both apoLp-Gln-I preparations produced doublet bands. The faster migrating band was considered to be the monomeric form of apoLp-Gln-I and the slower migrating band a polymeric form. In unlyophilized preparations of normal apoLpGln-I, only the faster band was seen; but, because of the low concentration of the Tangier apoLp-Gln-I sample, both the normal and Tangier apoLp-Gin-I samples were concentrated by lyophilization before electrophoresis at $\mathrm{pH}$ 2.9. Concentration was avoided in the experiment at $\mathrm{pH} 9.4$ by using extra long stacking gels. Rudman, Garcia, and Howard (5) have previously shown that lyophilization produces polymeric forms of apoLp-Gln-I on polyacrylamide gel electrophoresis. In addition, both bands were absorbed when the Tangier and normal apoLp-Gln-I preparations were passed over a column of Sepharose anti-apoLp-Gln-I. Normal and Tangier apoLp-Gln-I were also identical when tested by immunoelectrophoresis (Fig. 10C) and double immunodiffusion (Fig. 10D) against four antisera to HDL (antiHDL-1 to anti-HDL-4) and the antiserum to HDL. Immunoelectrophoresis of a concentrated portion of Tangier apoLp-Gln-I $(0.5 \mathrm{mg} / \mathrm{ml})$ produced only a single line against antihuman whole serum or antiHDL-1 and did not react with antisera to human albumin or human LDL.

The Tangier and normal apoproteins were further compared by amino acid analysis (Table III). The com-

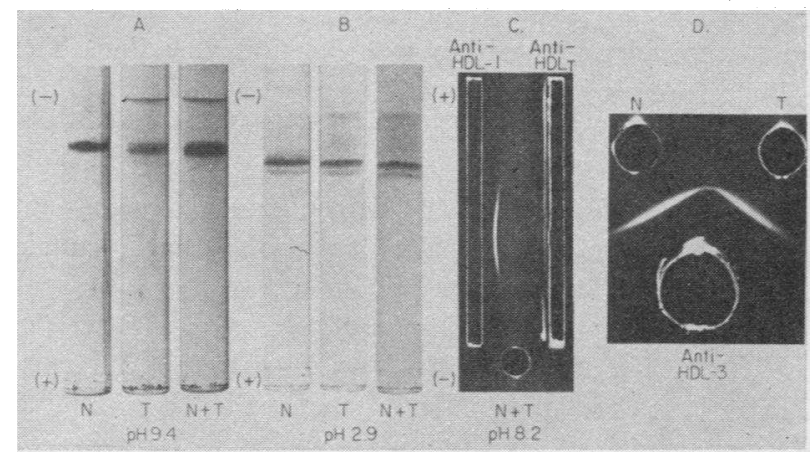

Figure 10 Comparison of Tangier and normal apoLp$G \ln -I$. A, polyacrylamide gels contained $7.5 \mu \mathrm{g}$ of either Tangier (T) or normal (N) apoLp-Gln-I or $7.5 \mu \mathrm{g}$ of each $(\mathrm{N}+\mathrm{T})$, and were run as described in Fig. 6; $\mathrm{B}$, same samples run at $\mathrm{pH} 2.9$; C, immunoelectrophoresis in agarose of a mixture of equal amounts of Tangier and normal apoLp-Gln-I $(\mathrm{N}+\mathrm{T})$ against anti-HDL-1 and anti-HDL $\mathrm{T}_{\mathrm{T}}$ (photograph at $24 \mathrm{hr}$ ); D, immunodiffusion in agarose of equal amounts of Tangier $(\mathrm{T})$ and normal $(\mathrm{N})$ apoLp-Gln-I against anti-HDL-3. The antigen concentration was $0.1 \mathrm{mg} / \mathrm{ml}$. Photograph at $36 \mathrm{hr}$. 
TABLE III

Amino Acid Composition of Tangier and Normal apoLp-Gln-I and apoLp-Gln-II

\begin{tabular}{|c|c|c|c|c|c|c|}
\hline \multirow[b]{2}{*}{ Amino acid $\ddagger$} & \multicolumn{3}{|c|}{ ApoLp-Gln-I* } & \multicolumn{3}{|c|}{ ApoLp-Gln-II* } \\
\hline & Tangier & Normal & $\begin{array}{c}\text { Range of } \\
\text { published } \\
\text { values§ }\end{array}$ & Tangier & Normal & $\begin{array}{c}\text { Range of } \\
\text { published } \\
\text { values§ }\end{array}$ \\
\hline Aspartic acid & 8.9 & 9.9 & $8.3-9.8$ & 4.5 & 5.2 & $4.1-5.4$ \\
\hline Threonine & 5.1 & 4.2 & $3.8-4.3$ & 7.9 & 7.6 & $7.0-8.2$ \\
\hline Serine & 7.4 & 5.9 & $5.4-6.3$ & 7.7 & 7.7 & $7.2-8.2$ \\
\hline Glutamic acid & 18.9 & 19.7 & $16.4-19.2$ & 21.2 & 20.5 & $19.6-20.7$ \\
\hline Proline & 4.2 & 4.2 & $3.7-5.0$ & 5.0 & 4.9 & $3.9-5.1$ \\
\hline Glycine & 6.8 & 4.7 & $4.4-4.6$ & 4.4 & 5.0 & $3.7-4.6$ \\
\hline Alanine & 7.8 & 8.1 & $7.3-7.6$ & 6.6 & 7.0 & $6.4-6.9$ \\
\hline Valine & 5.3 & 5.6 & $5.1-5.8$ & 7.6 & 7.5 & $6.9-7.7$ \\
\hline Methionine & 0.7 & 1.1 & $0.8-1.5$ & 0.6 & 0.9 & $1.3-1.7$ \\
\hline Isoleucine & 1.3 & 0.2 & $0.0-0.2$ & 1.1 & 1.7 & $1.5-2.0$ \\
\hline Leucine & 12.8 & 15.2 & $14.8-16.7$ & 10.4 & 11.0 & $9.8-10.3$ \\
\hline Tyrosine & 2.5 & 2.3 & $2.3-3.3$ & 4.8 & 4.0 & $3.9-4.1$ \\
\hline Phenylalanine & 3.3 & 2.3 & $2.3-3.1$ & 5.0 & 4.9 & $4.0-5.0$ \\
\hline Lysine & 9.1 & 9.0 & $7.5-9.5$ & 12.5 & 11.7 & $11.5-12.9$ \\
\hline Histidine & 1.2 & 1.6 & $1.7-2.3$ & 0.0 & 0.1 & $0.0-0.4$ \\
\hline Arginine & 4.8 & 6.0 & $6.0-6.7$ & 0.1 & 0.4 & $0.0-0.9$ \\
\hline Half-cystine & $\cdots$ & & 0.0 & $\ldots$ & - & $2.4-3.0$ \\
\hline Tryptophan! & - & - & $1.3-2.6$ & -- & -- & 0.0 \\
\hline
\end{tabular}

\footnotetext{
* The amino acid composition is expressed as moles $/ 10^{2}$ moles. The values for the Tangier and normal apoLp-Gln-II and the normal apoLp-Gln-I samples were the average of duplicate de-

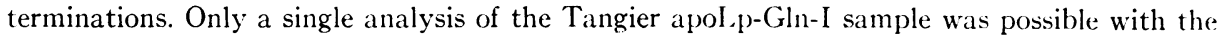
limited amount of material available.

$\ddagger$ No correction was made for possible degradation or incomplete hydrolysis of particular residues.

$\S$ Values are those of Shore and Shore (3), Scanu et al. (t), and Rudman et al. (5).

II These residues were completely destroyed under the hydrolysis conditions used $(6 \times \mathrm{HCl}$,

$\left.22 \mathrm{hr}, 110^{\circ} \mathrm{C}\right)$
}

positions of the normal and Tangier apoLp-Gln-II samples were identical within experimental variation. The compositions of the normal and Tangier apoLp-Gln-I samples were similar but not identical. The percentages of threonine, serine, glycine, isoleucine, and phenylalanine were higher and the percentages of leucine and arginine lower in the Tangier apoL $\mathrm{p}-\mathrm{Gln}-\mathrm{I}$ sample compared with normal apoLp-Gln-I.

Amounts of apoLp-Gln-I and apoLp-Gln-II in the HDL fraction of normal and Tangier plasma. The concentrations of apoLp-Gln-I, apoLp-Gln-II, and the "minor proteins" in the high density lipoproteins of normal and Tangier plasma were estimated from the quantity of HDL or HDL $\mathrm{T}_{\mathrm{T}}$ protein isolated per $100 \mathrm{ml}$ of plasma and the percentage composition obtained from Sephadex G-200 chromatography on the same preparations. The results are expressed in Table IV. Both apoLp-Gln-I and apoLp-Gln-II were decreased in the d $1.063-1.210 \mathrm{~g} / \mathrm{ml}$ fraction of Tangier plasma, apoL $\mathrm{L}^{\text {- }}$ Gln-II to $6.0 \%$, and apoLp-Gin-I to $0.16 \%$ of the concentration in the normal subject. Thus, apoLp-Gln-I was disproportionately decreased 36 times more than apoLp-Gln-II. The proportion of the minor proteins to the total protein was approximately the same in HDL as in HDL.

Total contcnt of apoL-p-Gln-I and apoLp-Gln-II in normal and Tangicr plasma. Additional experiments were performed to determine whether there was an absolute decrease in the amount of apoLp-Gln-I and apoLpGIn-II in Tangier plasma, or whether the decrease in these apoproteins in the HDL region could be due to their preferential segregation with the other lipoprotein fractions of $\mathrm{d}<1.063 \mathrm{~g} / \mathrm{ml}$ or with the plasma proteins of $\mathrm{d}>1.210 \mathrm{~g} / \mathrm{ml}$. The total amount of apoLp-Gln-I and apoLp-Gln-II in Tangier and normal plasmas was estimated by determining the anti-apoLp-Gin-I and antiapoLp-Gln-II reactivity remaining after absorption of $1.0 \mathrm{ml}$ of anti-HDL-1 with either 0.3 or $1.0 \mathrm{ml}$ of Tangier or normal plasma (Table V). Plasma from four Tangier patients (Pe. Lo., Pa. Lo., T. La., and E. La.) and three normal subjects was tested. All of the antiapoLp-Gln-I and anti-apoLp-Gin-II reactivity was re- 
moved by $0.2 \mathrm{ml}$ of normal plasma, but the same amount of Tangier plasma decreased the anti-apoLpGln-I and anti-apoLp-Gln-II reactivities only slightly. The range of antigen: antibody ratios after absorption with $0.2 \mathrm{ml}$ of any one of the four Tangier plasmas was $>1: 0.5$ to $1: 2.5$ (apoLp-Gln-I), $>1: 0.5$ to $1: 10$ (apoLp-Gln-II) and $>1: 0.5$ (saline control). However, after absorption of $1.0 \mathrm{ml}$ of anti-HDL-1 with $1.0 \mathrm{ml}$ of the Tangier plasmas, all of the anti-apoLp-Gln-II reactivity was removed while only a small additional increment of anti-apoLp-Gin-I reactivity was removed (range of antigen: antibody ratios $-1: 2.5$ to $1: 10$, saline control $=1: 2.5$ ).

Hence, there is an absolute decrease in the amount of immunochemically recognizable apoLp-Gln-I and apoLp-Gln-II in Tangier plasma, and the disproportionate decrease in apoLp-Gln-I exists in the whole plasma as well as in the HDL fraction. Normally HDL apoproteins are detectable immunochemically in the lipoproteins of $\mathrm{d}<1.063 \mathrm{~g} / \mathrm{ml}(32,53)$. Small amounts of both apoLp-Gln-I and apoLp-Gln-II have been identified. ${ }^{5}$ In addition, apoLp-Gln-I is easily dissociated from HDL by storage or ultracentrifugation and is subsequently recovered in the fraction of $\mathrm{d}>1.210 \mathrm{~g} / \mathrm{ml}(37,54)$. In order to exclude preferential segregation of the Tangier apoproteins with these "non-HDL" fractions, the concentrations of apoLp-Gin-I and apoLp-Gln-II were also estimated in the fractions of $d<1.063 \mathrm{~g} / \mathrm{ml}$ and $\mathrm{d}>1.210 \mathrm{~g} / \mathrm{ml}$ from Tangier and normal plasma and in the infranatant fractions obtained when HDL and HDL were washed by reflotation at $\mathrm{d}>1.210 \mathrm{~g} / \mathrm{ml}$. Each Tangier fraction contained much less apoLp-Gin-I and apoLp-Gin-II than its normal counterpart and relatively more apoLp-Gln-II than apoLp-Gin-I.

\section{DISCUSSION}

An understanding of the protein defect in Tangier disease is gradually evolving. In the initial reports of this entity, trace amounts of HDL of uncertain identification were detected (27-29). The data in the present report provide unequivocal evidence that patients with Tangier disease have small amounts of HDL in their plasma that is similar but not identical with the normal lipoproteins of this density class. The Tangier HDL, designated as $\mathrm{HDL}_{\mathrm{T}}$, is present in the usual density range of $1.063-$ 1.210 , is not precipitated by heparin and manganese, and contains cholesterol, cholesteryl esters, and phospholipids in roughly the same proportion as normal HDL. The triglyceride content may be slightly higher than normal, a possible abnormality that has been earlier emphasized by Kocen, Lloyd, Lascelles, Fosbrooke, and Williams (2).

\footnotetext{
${ }^{5}$ Bilheimer, D., and S. Lux. Unpublished observations.
}

TABLE IV

Comparison of the Amounts of apoLp-Gln-I and apoLpGln-II in the d 1.063-1.210 Fraction of Normal and Tangier Plasma

\begin{tabular}{|c|c|c|c|}
\hline & $\begin{array}{l}\text { Concentration } \\
\text { in d } 1.063- \\
1.210 \text { fraction } \\
\text { of normal } \\
\text { control }\end{array}$ & $\begin{array}{l}\text { Concentration } \\
\text { in d 1.063- } \\
1.210 \text { fraction } \\
\text { of Tangier } \\
\text { patient } \\
\text { (Pa. Lo.) }\end{array}$ & $\begin{array}{c}\% \text { of } \\
\text { Tangier } \\
\text { patient } \\
\text { compared } \\
\text { with } \\
\text { control }\end{array}$ \\
\hline $\mathrm{HDL}$ or $\mathrm{HDL}_{\mathrm{T}}{ }^{*}$ & $\begin{array}{c}m g / 100 m l \\
87.0\end{array}$ & $\begin{array}{c}m g / 100 \mathrm{ml} \\
1.6\end{array}$ & $\begin{array}{r}\% \\
1.8\end{array}$ \\
\hline apoLp-Gln-I & 60.0 & 0.1 & 0.16 \\
\hline apoLp-Gln-II & 20.0 & 1.3 & 6.0 \\
\hline Minor proteins & 6.1 & 0.008 & 1.3 \\
\hline
\end{tabular}

* Concentrations are low because of material lost in washings. $\ddagger$ Calculated from HDL concentrations and per cent of apoLpGln-I, apoLp-Gln-II, and minor proteins as obtained by Sephadex G-200 chromatography of these same preparations. Concentrations of the three fractions do not add up to the concentrations of $\mathrm{HDL}$ or $\mathrm{HDL}_{\mathrm{T}}$ since the material in the void volume peak is not included.

These data on the lipid composition of HDL must be considered only approximate, however, since they are not corrected for any possible contamination of "sinking prebeta lipoprotein" ( $\mathrm{Lp}(\mathrm{a})$ antigen) which is also found in the fraction of $d>1.063$ (55). The existence of such a contaminant in HDL is suggested by

\section{TABLE V}

Immunochemical Comparison of the apoLp-Gln-I and apoLpGln-II Content of Tangier and Normal Plasma

\begin{tabular}{|c|c|c|c|}
\hline $\begin{array}{l}\text { Anti-HDL-1 } \\
\text { absorbed with* }\end{array}$ & $\begin{array}{l}\text { Amount of } \\
\text { absorbent }\end{array}$ & Antigen & $\begin{array}{l}\text { Range of } \\
\text { antigen: } \\
\text { antibody } \\
\text { ratios }\end{array}$ \\
\hline & $m l$ & & $\mu g: \mu l$ \\
\hline \multirow[t]{2}{*}{ Saline } & 0.2 & apoLp-GIn-II & $>1: 0.5$ \\
\hline & 1.0 & apoLp-Gln-II & $>1: 0.5$ \\
\hline \multirow[t]{2}{*}{ Tangier plasmas (4) } & 0.2 & apoLp-Gln-II & $>1: 0.5-1: 10$ \\
\hline & 1.0 & apoLp-Gln-II & $<1: 200$ \\
\hline \multirow{2}{*}{ Normal plasmas (3) } & 0.2 & apoLp-Gin-II & $<1: 200$ \\
\hline & 1.0 & apoLp-Gln-II & $<1: 200$ \\
\hline \multirow[t]{2}{*}{ Saline } & 0.2 & apoLp-Gln-I & $>1: 0.5$ \\
\hline & 1.0 & apoLp-Gln-I & $1: 2.5$ \\
\hline \multirow[t]{2}{*}{ Tangier plasmas (4) } & 0.2 & apoLp-Gln-I & $>1: 0.5-1: 2.5$ \\
\hline & 1.0 & apoLp-Gln-I & $1: 2.5-1: 10$ \\
\hline \multirow[t]{2}{*}{ Normal plasmas (3) } & 0.2 & apoLp-Gln-I & $<1: 200$ \\
\hline & 1.0 & apoLp-Gln-I & $<1: 200$ \\
\hline
\end{tabular}

* $1 \mathrm{ml}$ of anti-HDL-1 was absorbed with 0.2 or $1.0 \mathrm{ml}$ of normal or Tangier plasma or with saline. The supernates were harvested, and the anti-apoLpGln-I and anti-apoLp-Gln-II activity remaining was determined as described in Methods. An antigen:antibody ratio of 1:0.5 represents a greater antibody titer than 1:2.5 or 1:10. An antigen:antibody ratio $<1: 200$ indicates no reaction was seen. All reactions were run on the same day. Antigen concentrations were $0.1 \mathrm{mg} / \mathrm{ml}$. The numbers in parentheses indicate the number of subjects studied. 
the presence of a band that reacts with LDL antisera and migrates with prebeta mobility on immunoelectrophoresis (Fig. 1D) and by unpublished observations (in collaboration with Dr. T. Forte, Berkeley, Calif.) in which particles compatible with $\mathrm{L}_{\mathrm{p}}(\mathrm{a})$ antigen (56) were observed on electron microscopy of HDLr. The contribution of such a contaminant to the lipid composition of the high density fraction, while normally small, could be significant in Tangier disease due to the 50-to100 -fold reduction in the amount of HDL. Further detailed examination of the lipid composition and physical properties of purified HDL ${ }_{\mathrm{T}}$ and of the other lipoproteins in Tangier plasma is still needed.

$\mathrm{HDL}_{\mathrm{T}}$ cross-reacts with antisera to HDL, but is distinguished from normal HDL by slightly slower electrophoretic mobility. The observation of both HDL and HDL $_{\mathbf{r}}$ in the plasma of Tangier heterozygotes and in a homozygous individual following infusion of HDL during surgery confirms the difference in electrophoretic mobility of the isolated lipoproteins and eliminates the possibility that HDL $\mathrm{H}_{\mathrm{T}}$ is produced artifactually during the preparation of Tangier HDL.

The studies of the composition of $\mathrm{HDL}_{\mathrm{r}}$ suggests a basis for this immunochemical discrimination. HDL contains proportionately much less apoLp-Gln-I and more apoLp-Gln-II than normal HDL, the ratio of apoLp-Gln-I to apoLp-Gln-II being about $1: 12$ instead of the usual $3: 1$. ApoLp-Gln-II has a slower mobility on immunoelectrophoresis than apoLp-Gln-I (Fig. 4); and HDLt might be expected, on the basis of its higher content of apoLp-Gln-II to have a slower mobility than HDL. This does not exclude the possibility that the differences in lipid composition or that still undetected differences in carbohydrate composition might also contribute to the different electrophoretic mobilities of HDL and HDL.

Despite this new insight into the apoprotein composition of $\mathrm{HDL}_{\mathrm{T}}$, the nature of the genetic alteration that underlies Tangier disease remains speculative. If we assume the defect is limited to a single allele, the disproportionate decrease in apoLp-Gln-I suggests this apoprotein is the product of the defective gene. Because the Tangier HDL apoproteins have no detectable differences from their normal counterparts in size, charge, or immunochemical reactivity; it is tempting to infer that a mutation in an allele-regulating synthesis rather than structure of apoLp-Gln-I is involved.

Such an hypothesis is always of considerable interest, since existence of a mutation analogous to the regulatory gene mutations discovered in microorganisms by Jacob and Monod (57) has yet to be proved in man. Nevertheless, the possibility of a structural gene abnormality in Tangier disease has not been excluded. As in the recent example of the Hektoen variant of glucose-6-phosphate dehydrogenase $(58,59)$, postulated regulatory mutations have often yielded to eventual discovery of a structural alteration in the protein in question.

At the present time, the only evidence suggesting a structural mutation in either of the Tangier aproproteins is the observation of minor differences in the amino acid composition between the Tangier and normal apoLp-Gln-I samples. Since the observed differences involved several amino acids the most plausible explanation is that the apoprotein samples included small amounts of other proteins or amino acids, contamination that would have been considerably amplified by the marked decrease in the quantity of Tangier apoLpGln-I compared with normal apoLp-Gln-I. Mutations resulting in the addition or deletion of multiple amino acids have been described (60-62). However, such extensive changes in the composition of the Tangier apoLp-Gln-I would likely have altered the electrophoretic or immunochemical properties of the mutant protein. In either case, additional studies, including peptide mapping and possibly even determination of the amnio acid sequence of the HDL apoproteins, will be required to substantiate or refute the presence of a regulatory mutation.

A corollary of the hypothesis that the mutation is limited to a single allele-regulating apoLp-Gln-I synthesis is that the synthesis of other HDL apoproteins should be normal. As shown in Table IV and V, however, the concentration of both apoLp-Gln-I and apoLpGln-II is decreased in Tangier plasma. There are several possible explanations for this apparent paradox. We believe it likely that the mutant $\mathrm{HDL}_{\mathrm{T}}$ complex containing essentially only apoLp-Gln-II is unstable and is rapidly removed from the circulation. Alternatively, it is possible that apoLp-Gln-II, though synthesized normally, is not easily released from the liver cell (63) in the absence of apoLp-Gln-I. A third possibility is that the synthesis of apoLp-Gln-II is also decreased but to a lesser extent than apoLp-Gln-I. This could occur if the structural genes for apoLp-Gln-I and apoLp-Gln-II were controlled by a single mutant genome or if Tangier patients were doubly heterozygous for mutant alleles affecting both apoLp-Gln-I and apoLp-Gln-II production. Quantitation of apoLp-Gln-I and apo-Gln-II in HDL from Tangier heterozygotes and radioactive turnover studies of $\mathrm{HDL}_{\mathrm{T}}$ should allow discrimination between some of these possibilities.

Insofar as could be determined from examination of plasma from over 300 subjects with normal lipoprotein concentrations or other types of dyslipoproteinemia, HDL $_{\text {т }}$ appears to be a unique marker for Tangier disease. From samples generously provided by their physicians, we have been able to demonstrate $\mathrm{HDL}_{\mathrm{r}}$ in the 
plasmas of single patients with Tangier disease from Britain, Germany, and New Zealand (1) in addition to the seven described here. Thus, HDL mon to all patients with Tangier disease whose plasma has been appropriately examined.

From experiments employing immunoelectrophoresis, it appears that the obligatory heterozygote for Tangier disease also has circulating HDLr. It has not yet been possible to confirm this by isolation of the abnormal lipoprotein or to obtain meaningful estimates of the relative amounts of $\mathrm{HDL}$ and $\mathrm{HDL}_{\mathbf{r}}$ in the plasma of heterozygotes. The demonstration of HDL $\mathrm{T}$ in the heterozygote offers an opportunity to use a specific determinant of the carrier state for this rare disease, a simple decrease in HDL concentration having been previously recognized as a nonspecific test for the heterozygous phenotype (29). The need for prior reduction of HDL concentration in the heterozygote by high carbohydrate feeding, however, makes the immunochemical test for HDL impractical. The simpler expedient of diluting the plasma to enhance detection of $\mathrm{HDL}_{\mathrm{T}}$ has not yet been tested in an adequate number of subjects to prove its infallibility.

\section{ACKNOWLEDGMENTS}

We wish to thank Ms. Kathryn John for invaluable assistance with lipoprotein preparation and polyacrylamide gel electrophoresis; Ms. Silja Meret for assistance with the amino acid analyses; Dr. Pedro Cuatrecasas for advice on the preparation of the agarose-bound antigens and antibodies; Dr. Ralph Reisfeld for permitting us to use his unpublished pH 2.9 gel electrophoresis system; and Dr. Gilbert Owen for helpful suggestions on the genetic analysis.

\section{REFERENCES}

1. Fredrickson, D. S., A. M. Gotto, and R. I. Levy. 1972. Familial lipoprotein deficiency. In The Metabolic Basis of Inherited Disease. (Abetalipoproteinemia, hypobetalipoproteinemia, and Tangier disease). J. B. Stanbury, J. B. Wyngaarden, and D. S. Fredrickson, editors. McGraw-Hill Book Company, New York. 3rd edition. 493.

2. Kocen, R. S., J. K. Lloyd, P. T. Lascelles, A. S. Fosbrooke, and D. Williams. 1967. Familial alpha-lipoprotein deficiency (Tangier disease) with neurological abnormalities. Lancet. 1: 1341.

3. Shore, B., and V. Shore. 1969. Isolation and characterization of polypeptides of human serum lipoproteins. Biochemistry. 8: 4510.

4. Scanu, A., J. Toth, C. Edelstein, S. Koga, and E. Stiller. 1969. Fractionation of human serum high density lipoprotein in urea solutions. Evidence for polypeptide heterogeneity. Biochemistry. 8: 3309.

5. Rudman, D., L. A. Garcia, and C. H. Howard. 1970. A new method for isolating the nonidentical protein subunits of human plasma $\alpha$-lipoprotein. J. Clin. Invest. 49: 365.

6. Kostner, G., and P. Alaupovic. 1971. Studies of the composition and structure of plasma lipoproteins. C- and N-terminal amino acids of the two nonidentical polypeptides of human plasma apolipoprotein A. (FEBS (Fed. Eur. Biochem. Soc.) Lett. 15: 320

7. Alaupovic, P. 1972. Conceptual development of the classification systems of plasma lipoproteins. 19th Annual Colloquim on Protides of the Biological Fluids. $H$. Peters, editor. Pergamon Press, Inc., Elmsford, N. Y. 19th edition. 9.

8. Brown, W. V., R. I. Levy, and D. S. Fredrickson. 1969. Studies of the proteins in human plasma very low density lipoproteins. J. Biol. Chem. 244 : 5687.

9. Brown, W. V., R. I. Levy, and D. S. Fredrickson. 1970. Further characterization of apolipoproteins from the human plasma very low density lipoproteins. J. Biol. Chem. 245 : 6588.

10. Herbert, P., R. I. Levy, and D. S. Fredrickson. 1971. Correction of $\mathrm{COOH}$-terminal amino acids of human plasma very low density apolipoproteins. J. Biol. Chem. 246: 7068.

11. McConathy, W. J., C. Quiroga, and P. Alaupovic. 1972. Studies of the composition and structure of plasma lipoproteins. $\mathrm{C}$ - and $\mathrm{N}$-terminal amino acids of C-I polypeptide ("R-Val") of human plasma apolipoprotein C. FEBS (Fed. Eur. Biochem. Soc.) Lett. 19: 323.

12. Brewer, H. B., Jr., R. Shulman, P. Herbert, R. Ronan, and K. Wehrly. 1972. The complete amino acid sequence of an apolipoprotein obtained from human very low density lipoprotein (VLDL). Adv. Exp. Med. Biol. 5: 280.

13. Brewer, H. B., Jr., S. E. Lux, R. Ronan, and K. M. John. 1972. The amino acid sequence of apoLp-Gin-II (ApoA-II), an apolipoprotein isolated from the high density lipoprotein complex. Proc. Natl. Acad. Sci. U.S. A. 69: 1304.

14. Scanu, A. M., C. Edelstein, and C. T. Lim. 1971. Effect of disulfide cleavage on the molecular weight of one of the major polypeptides of human serum high density lipoprotein. FEBS (Fed. Eur. Biochem. Soc.) Lett. 18: 305.

15. Scanu, A., E. Cump, J. Toth, S. Koga, E. Stiller, and L. Albers. 1970. Degradation and reassembly of a human serum high density lipoprotein. Evidence for differences in lipid affinity among three classes of polypeptide chains. Biochemistry. 9: 1327.

16. Lux, S. E., R. Hirz, R. I. Shrager, and A. M. Gotto. 1972. The influence of lipid on the conformation of human plasma high density apolipoproteins. J. Biol. Chem. 247: 2598.

17. Albers, J. J., and F. Aladjem. 1971. Precipitation of ${ }^{125}$ I-labeled lipoproteins with specific polypeptide antisera. Evidence for two populations with differing polypeptide compositions in human high density lipoproteins. Biochemistry. $10: 3436$.

18. Shore, V., and B. Shore. 1968. Some physical and chemical studies on two polypeptide components of high-density lipoproteins of human serum. Biochemistry. 7: 3396 .

19. Shore, B., and V. Shore. 1972. Structure of normal and pathological lipoproteins. In Proceedings of the European Society of Atherosclerosis. Massoon et Cie, Paris. In press.

20. LaRosa, J. C., R. I. Levy, P. N. Herbert, S. E. Lux, and D. S. Fredrickson. 1970. A specific apoprotein 
activator for lipoprotein lipase. Biochem. Biophys. Res. Commun. $41: 57$.

21. Havel, R. J., V. G. Shore, B. Shore, and D. M. Bier. 1970. Role of specific glycopeptides of human serum lipoproteins in the activation of lipoprotein lipase. Circ. Res. $27: 595$.

22. Ganesan, D., R. H. Bradford, P. Alaupovic, and W. J. McConathy. 1971. Differential activation of lipoprotein lipase from human post-heparin plasma, milk and adipose tissue by polypeptides of human serum apolipoprotein C. FEBS (Fed. Eur. Biochcm. Soc.) Lett. 15: 205.

23. Fielding, C. J., V. G. Shore, and P. E. Fielding. 1972. A protein cofactor of lecithin: cholesterol acyltransferase. Biochem. Biophy's. Res. Commun. 46: 1493.

24. Dempsey, M. E., M. C. Ritter, and S. E. Lux. 1972. Functions of a specific plasma apolipoprotein in cholesterol biosynthesis. Fed. Proc. 31: 430.

25. Bilheimer, D. W., S. Eisenberg, and R. I. Levy. 1972. The metabolism of VLDL proteins I. Preliminary in vitro and in aivo observations. Biochim. Biophys. Acta. $260: 212$.

26. Levy, R. I., and D. S. Fredrickson. 1966. Nature of the alpha lipoproteins in Tangier disease. Circulation. 34 (Suppl. III) : 156.

27. Fredrickson, D. S., P. H. Altrocchi, L. V. Avioli, D. S. Goodman, and H. C. Goodman. 1961. Tangier disease. Ann. Intern. Med. 55: 1016.

28. Fredrickson, D. S., and P. H. Altrocchi. 1962. Tangier disease (familial cholesterolosis with high density lipoprotein deficiency). In Cerebral Sphingolipidoses. S. M. Aronson and B. W. Volk, editors. Academic Press, Inc., New York. 343.

29. Fredrickson, D. S. 1964. The inheritance of high density lipoprotein deficiency (Tangier disease). J. Clin. Ini'est. $43: 228$.

30. Engel, W. K., J. D. Dorman, R. I. Levy, and D. S. Fredrickson. 1967. Neuropathy in Tangier Disease. Alpha-lipoprotein deficiency manifesting as familial recurrent neuropathy and intestinal lipid storage. Arch. Neurol. $17: 1$.

31. Smith, S. C., R. L. Scheig, G. Klatskin, and R. I. Levy, 1967. Lipoprotein abnormalities in liver disease. Clin. Res. $15: 330$

32. Levy, R. I., R. S. Lees, and D. S. Fredrickson. 1966. The nature of pre-beta (very low density) lipoproteins. J. Clin. Invest. $45: 63$.

33. Havel, R. J., H. A. Eder, and J. H. Bragdon. 1955. The distribution and chemical composition of ultracentrifugally separated lipoproteins in human serum. $J$. Clin. Invest. 34: 1345.

34. Fredrickson, D. S., R. I. Levy, and F. T. Lindgren. 1968. A comparison of heritable abnormal lipoprotein patterns as defined by two different techniques. J. Clin. Invest. $47: 2446$.

35. Fredrickson, D. S., R. I. Levy, and R. S. Lees. 1967. Fat transport in lipoproteins-an integrated approach to mechanisms and disorders. N. Engl. J. Med. 276: $34,94,148,215,273$.

36. Burstein, M., and J. Samaille. 1960. Sur un dosage rapide du cholesterol lié aux $\alpha$ - et $\beta$-lipoprotéines du sérum. Clin. Chim. Acta. 5: 609.

37. Levy, R. I., and D. S. Fredrickson. 1965. Heterogeneity of plasma high density lipoproteins. J. Clin. Ini'est. $44: 426$.
38. Gotto, A. M., and H. Kon. 1970. Observations on the conformation of human serum high-density lipoproteins using infrared spectroscopy, circular dichronism and electron spin resonance. Biochemistry. 9: 4276.

39. Marier, J. R., and D. Rose. 1964. Determination of cyanate and a study of its accumulation in aqueous solutions of urea. Anal. Biochcm. 7: 304.

40. Winzor, D. J. 1969. Analytical gel filtration. In Physical Principles and Techniques of Protein Chemistry. Part A. S. J. Leach, editor, Academic Press, Inc., New York. 451.

41. Piazzi, S. E. 1969. A simple method for preliminary immunodiffusion test of antigen-antibody systems having unknown ratios of reaction. Anal. Biochem. 27: 281.

42. Campbell, D. H., J. S. Garvey, N. E. Cremer, and D. H. Sussdorf. 1963. Methods of Immunology. W. A. Benjamin, Inc., Menlo Park, Calif.

43. Cuatrecasas, P. 1970. Protein purification by affinity chromatography. Derivatizations of agarose and polyacrylamide heads. J. Biol. Che'm. 245: 3059.

44. Reisfeld, R. A., and P. A. Small, Jr. 1966. Electrophoretic heterogeneity of polypeptide chains of specific antibodies. Science (Wash. D. C.). 152: 1253.

45. Chrambach, A., R. A. Reisfeld, M. Wyckoff, and J. Zaccari. 1967. A procedure for rapid and sensitive staining of protein fractionated by polyacrylamide gel electrophoresis. Anal. Biochem. 20: 150.

46. Hubbard, R. W., and D. M. Kremen. 1965. Increased sensitivity of accelerated amino acid ion-exchange chromatography. Anal. Biochem. 12: 593.

47. Hubbard, R. W. 1965. Studies in accelerated amino acid analysis. Biochem. Biophy's. Res. Commun. 19: 679.

48. Lowry, O. H., N. J. Rosebrough, A. L. Farr, and R J. Randall. 1951. Protein measurement with the Folin phenol reagent. J. Biol. Chcm. 193: 265.

49. Total Cholesterol procedure N-246. In Auto-analyses Manual. 1964. Technicon Instruments, Inc., Tarreytown, N. Y.

50. Bartlett, G. R. 1959. Phosphorus assay in column chromatography. J. Biol. Chem. 234: 466.

51. Kessler, G., and H. Lederer. 1966. Fluorometric measurement of triglycerides. In Technicon Symposium Automation in Analytical Chemistry. L. T. Skeggs, Jr., editor. Mediad, New York. 2: 341.

52. Lees, R. S., and F. T. Hatch. 1963. Sharper separation of lipoprotein species by paper electrophoreses in albumin-containing buffer. J. Lab. Clin. Mcd. 61: 518 .

53. Lee, D. M., and P. Alaupovic. 1970. Studies of the composition and structure of plasma lipoproteins. Isolation, composition and immunochemical characterization of low density lipoprotein subfractions of human plasma. Biochemistry. 9: 2244.

54. Nichols, A. V., S. Lux, J. Forte, E. Gong, and R. I. Levy. 1972. Degradation products from human serum high density lipoproteins following dehydration by rotary evaporation and solubilization. Biochim. Biophy's. Acta. 270: 132 .

55. Rider, A. K., R. I. Levy, and D. S. Fredrickson. 1970. "Sinking" pre-beta lipoprotein and the Lp antigen. Circulation. 42 (Suppl. III) : 10.

56. Simons, K., C. Ehnholm, O. Renkonen, and B. Bloth. 1970. Characterization of the $\mathrm{Lp}_{\mathrm{p}}(\mathrm{a})$ lipoprotein in 
human plasma. Acta Pathol. Microbiol. Scand. Sect. B: Microbiol. Immunol. 78 : 459.

57. Jacob, F., and J. Monod. 1961. Genetic regulatory mechanisms in the synthesis of proteins. J. Mol. Biol. 3: 318 .

58. Dern, R. J. 1966. A new hereditary quantitative variant of glucose-6-phosphate dehydrogenase characterized by a marked increase in enzyme activity. J. Lab. Clin. Med. 68: 560 .

59. Yoshida, A. 1970. Amino acid substitution (histidine to tyrosine) in a glucose-6-phosphate dehydrogenase variant (G6PD Hektoen) associated with over-production. J. Mol. Biol. 52 : 483.
60. Baglioni, C. 1962. The fusion of two peptide chains in hemoglobin Lepore and its interpretation as a genetic deletion. Proc. Natl. Acad. Sci. U. S. A. 48: 1880.

61. Flatz, G., J. L. Kinderlerer, J. V. Kilmartin, and H. Lehman. 1971. Haemoglobin Tak: a variant with additional residues at the end of the $\beta$-chains. Lancet. 1: 732.

62. Milner, P. F., J. B. Clegg, and D. J. Weatherall. 1971. Haemoglobin- $\mathrm{H}$ disease due to an unique haemoglobin variant with an elongated $\alpha$-chain. Lancet. 1: 729.

63. Bungenberg de Jong, J. J., and J. B. Marsh. 1968. Biosynthesis of plasma lipoproteins by rat liver ribosomes. J. Biol. Chem. 243: 192. 